6 Boeckh, J., Ernst, K. D., Sass, H., and Waldow, U., Verh. dt. zool. Ges. 9 (1976) 123.

7 Chambille, I., Rospars, J.P., and Masson, C., J. Neurobiol. 11 (1980) 135

8 Rospars, J.P., Jarry, C., and Chambille, I., C.r. Acad. Sci, Paris 296 (1983) 369.

9 Jawlowski, H., Annls Univ. Mariae Curie-Sklodowska, 3 (1948) 1.

10 Boeckh, J., Boeckh, V., and Kühn, A., in: 6th Cong. Int. Olfaction and Taste, Paris 1977, p. 315

11 Hildebrand, J.G., Matsumoto, S.G., Camazine, S.M., Tolbert, L.P., Blank, S., Ferguson, H., and Ecker, V., in: Insect Neurobiology and Pesticide Action, p. 375. Ed. Neurotox. Society for Chemical Industry, London 1980.

12 Boeckh, J., and Boeckh, V., J comp. Physiol. 132 (1979) 235

13 Masson, C., in: Symposium Les Phéromones Sexuelles et les Médiateurs Chimiques chez les Insectes, p.11. Institut National de la Recherche Agronomique, Colmar 1980.
14 Masson, C., and Brossut, R., La Recherche 12 (1981) 406.

15 Tyrer, N.M., and Altman, J.S., J. comp. Neurol. 157 (1974) 117

16 Arnold, G., Masson, C., and Budharugsa, S., Apidologie 14 (1983) 127.

17 Arnold, G., and Masson, C., C.r. Acad. Sci. Paris 292 (1981) 681

18 Masson, C., and Arnold, G., J. Insect Physiol. 30 (1984) 7.

19 Prillinger, L., Cell Tissue Res. 215 (1981) 563.

20 Suzuki, H., J. Insect Physiol. 21 (1975) 831.

21 Mobbs, P. G., Phil. Trans. R. Soc. Lond. B 298 (1982) 309.

22 Esslen, J., and Kaissling, K.E., Zoomorphologie 83 (1976) 227.

$0014-4754 / 84 / 070723-03 \$ 1.50+0.20 / 0$

(C) Birkhäuser Verlag Basel, 1984

\title{
A hypothalamic channel-system in the inferior lobes of a trigger-fish (Rhinecanthus aculeatus, Balistidae)
}

\author{
M. Wullimann, W. Finck and D. G. Senn \\ Zoological Institute, University of Basel, Rheinsprung 9, CH-4051 Basel (Switzerland), 24 August 1983
}

Summary. In the course of a general investigation of the optic system in some trigger-fishes, a hypothalamic, ventricular channelsystem with pores, leading to the outside of the brain, has been discovered in the inferior lobes of Rhinecanthus aculeatus (Balistidae). A description of the morphological relations of the channel-system to the blood-vessel-supply and the cranium suggests that the organ-systems involved form a functional unit. The possibility of a hormone-producing system is discussed in the light of physiological and ecological aspects.

A general morphological investigation of the optic system in balistid species ${ }^{2}$ seems to be useful for comparative morphological reasons, as reports on this subject in advanced teleost fish are infrequent and seem to be entirely absent for members of the family Balistidae (Tetraodontiformes) ${ }^{3-5}$.

The hypothalamus, which is indirectly ${ }^{3,5-8}$ connected to the optic system, deserves special attention, as, in teleosts, it is the most highly differentiated part of the diencephalon (unlike in most land vertebrates, for example) and displays structures unique to the fish: saccus vasculosus and lobi inferiores ${ }^{3,4}$ (figs $1,2 \mathrm{~b})$. It is in these latter structures that a peculiar ventricular channel-system has been found in Rhinecanthus aculeatus, a member of the family Balistidae.

Material and methods. Reconstructions were done on cross-section series $(14 \mu \mathrm{m})$ of heads of R. aculeatus. The cross-sections were impregnated with bodian-silver and counterstained with cresyl-violet ${ }^{9}$. Microphotographs were taken using a Zeiss Photomicroscope on a Agfapan 25-film.

Results. We report, to our knowledge for the first time, the existence of a hypothalamic ventricular channel-system in the inferior lobes of a teleost species (figs $2 a$ and $2 b)^{3-5,10-14}$.

The anatomical evidence suggests a functional unit, in which the following are involved: 1 . the central nervous system (ventricular channel-system and surrounding nucleus), 2. blood vessels (arterial and venous) and connective tissue, and 3 . bone structures (cranial base).

As a common feature in teleosts the 3 rd ventricle protrudes bilaterally into the paired inferior lobes with a lateral recessus, which is surrounded by a periventricular nucleus (nucleus periventricularis recessus lateralis) ${ }^{11,15}$. In $R$. aculeatus the lateral recessus has several ventro-median, channel-like extensions (figs $2 \mathrm{a}$ and $2 \mathrm{~b}$ ), reaching the medial surface of the inferior lobes. The same applies to the periventricular nucleus (fig. 3). The most caudally situated channels seem to be open, allowing direct contact between liquor cerebrospinalis and meninx primitiva (fig. 3).

It is in this particular region that fine vessels of a branch of the cranial portion of the vena cardinalis anterior lead to the me- ninx primitiva and the underlying connective tissue. The resulting dense venous network is located in a pouch of the cranial base, which, in contrast, closely ensheaths the meninx primitiva and hence, the central nervous system (fig. 2a) more rostrally as well as more caudally.

In addition, the periventricular nucleus is provided by a branch of the carotid artery, which on each side intrudes from a lateral position into the inferior lobe at the level of the rostral beginning of the lateral recessus, then reaches the periventricular nucleus and runs parallel with it caudally (figs $2 a$ and $2 b$ )

Discussion. From the point of view of comparative morphology, the ventricular channel-system described is a unique fea-

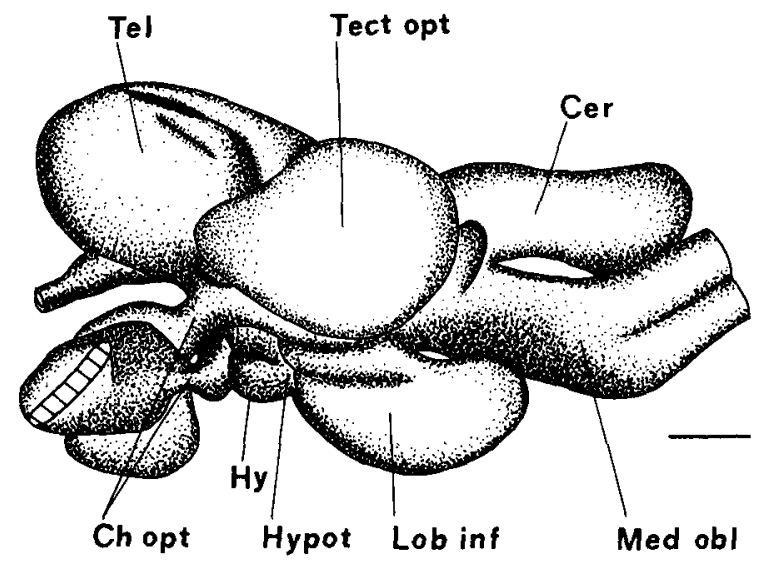

Figure 1. Brain of Rhinecanthus aculeatus in lateral view reconstruction (cranial nerves are not depicted). Hatched structure of the left optic nerve represents the optic papilla. Cer, corpus cerebelli; Hy, hypophysis; Hypot, hypothalamus; Lob inf, lobus inferior; Med obl, medulla oblongata; $\mathrm{Ch}$ opt, chiasma opticum; Tect opt, tectum opticum; Tel, telencephalon. Scale bar $1 \mathrm{~mm}$. 


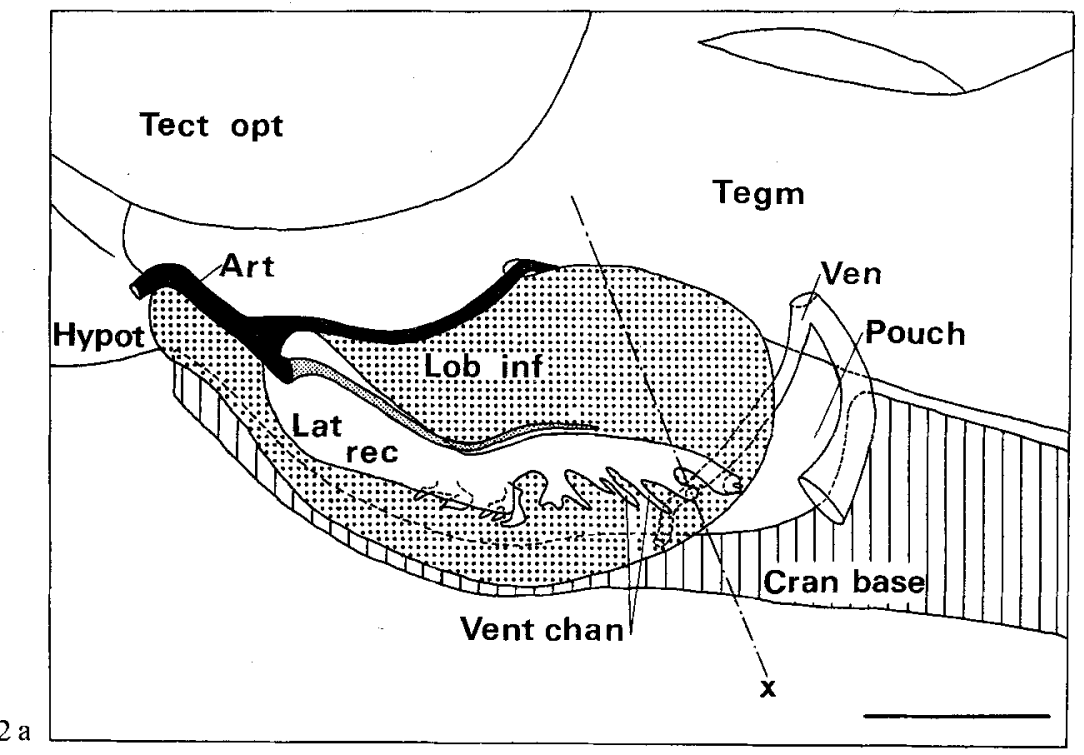

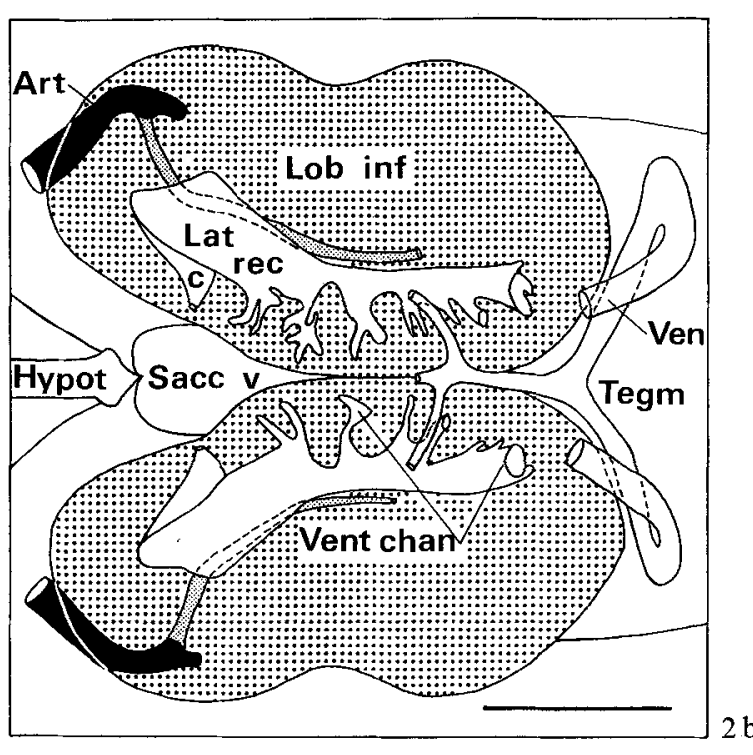

ture, and its appearance in related and non-related teleost groups needs to be evaluated. Only recently a comparable structure has been observed in a labrid fish, Coris julis ${ }^{16}$.

The anatomical evidence presented could support the hypothesis that there is a hormone-producing system in the inferior lobes of Rhinecanthus aculeatus. Generally, neurosecretory elements are known in teleosts $\mathrm{s}^{14,17,18}$ as in other vertebrates ${ }^{13}$ and are commonly designated as a part of the hypothalamo-hypophyseal system. In the special case of $R$. aculeatus 2 principal paths of information-flow can be discussed:

a) from the nucleus periventricularis to the hypophysis, which in turn would influence a presumptive gland (or target organ). A feedback from there would reach the nucleus periventricularis again by way of the venous network, and then the liquor cerebrospinalis.

b) From the nucleus periventricularis, which would in this case give direct information by way of the liquor cerebrospinalis and the venous network to a presumptive gland (or target organ), which in turn would give a feedback to the nucleus periventricularis by way of the arterial supply.

The 2nd way discussed receives some support from a recent HRP-study on the goldfish hypothalamo-hypophyseal system $^{17}$, in which connections between pituitary and some me-
Figure 2. Reconstruction of lateral view of the left inferior lobe (a) and of ventral view of both inferior lobes (b), showing the ventricular channel-system and its blood-vessel supply. Nucleus periventricularis recessus lateralis is not depicted, as it surrounds the lateral recessus of the 3 rd ventricle throughout its extension (see fig. 3). Art, branch of the carotid artery supplying nucleus periventricularis recessus lateralis (black: this branch lies on the surface of the inferior lobe, the dorsal part running to the tegmentum (not depicted in 2a), dotted: this branch runs into the inferior lobe and along the periventricular nucleus); $c$, connection between 3rd ventricle and its lateral recessus; Cran base, cranial base (showed in sagittal section); Hypot, hypothalamus; Lat rec, lateral recessus of the 3rd ventricle; Lob inf, lobus inferior; Pouch, pouch of the cranial base enclosing a venous network; Sace v, saccus vasculosus; Tegm, tegmentum (mesencephalon); Ven, branches of the cranial portion of vena cardinalis anterior; Vent chan, ventricular channel. Scale bar $1 \mathrm{~mm}$.

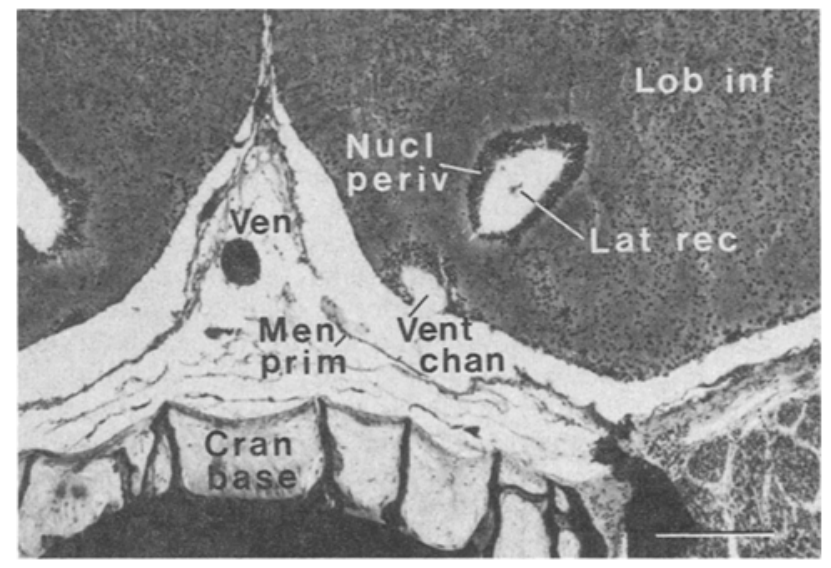

Figure 3. Cross-section of the left inferior lobe through the channel-system, plane of cross section is indicated in figure $2 \mathrm{a}$ with $\mathrm{x}$. Cran base, cranial base; Lat rec, lateral recessus of the third ventricle; Lob inf, lobus inferior; Men prim, meninx primitiva; Nucl periv, nucleus periventricularis recessus lateralis; Tegm, tegmentum; Ven, branch of the cranial portion of vena cardinalis anterior; Vent chan, ventricular channel. Scale bar $0.2 \mathrm{~mm}$. 
dian hypothalamic nuclei (nucleus preopticus pars magnocellularis and pars parvocellularis, nucleus lateralis tuberis ${ }^{17}$ ) have been observed, whereas no labelling occurred in neurons of the nucleus periventricularis recessus lateralis. In addition, a neurosecretory function of cells bordering the lateral recessus of the inferior lobes of Lepomis cyanellus and Carassius auratus has been proposed from electron microscopic evidence ${ }^{10}$.

The fact that the ventricular channel-system has pores seems to be unique among adult vertebrates. Openings in the neural tube of vertebrates are only known in transitional embryonic stages as neuroporus. This could affect a structural component of the blood-liquor barrier. The latter includes in general in the choroid plexus systems an endothelial (mesodermal) as well as an epithelial (neuroectodermal) component. Possible functions of a presumptive blood-liquor barrier (in the venous network) would therefore be either limited to the venous endothelium (as in the mammalian leptomeninx) or supplied at the ventricular ependyma (by a liquor-brain barrier).

Many advanced teleosts among perciform and tetraodontiform fish show a great ontogenetic plasticity of the following phenomena ${ }^{19-22}$ : growth and therefore size, social function and sex change. These features show a remarkable contrast to land vertebrates $^{23}$. Moreover, these developmental changes have been clearly demonstrated in Amphiprion species to depend on the dynamics of the social system in relation to the environment $^{20,22}$. Optical clues seem to play a predominant role in these biological changes.

However, a speculative idea could be admitted at this point: advanced teleost fish developed the complex vegetative regulatory systems in a new way. In addition to the hypophysis some advanced teleost fish possess a second area that can act as a bridge between neuronal and humoral processes.
1 Acknowledgments. We would like to thank R. Dätwyler for technical assistance and S.M. Kelly for critical reading of the manuscript.

2 Wullimann, M., $\mathrm{PhD}$ Thesis, in preparation.

3 Kuhlenbeck, H., The central nervous system of vertebrates, vol.3/I \& II,5/I. Springer, New York 1970/1973/1977.

4 Pearson, R., and Pearson, L., The vertebrate brain. Academic Press, London 1976.

5 Ariëns Kappers, C. U., Huber, G. C., and Crosby, E.C., The comparative anatomy of the nervous system of vertebrates. Hafner, New York 1936/1960

6 Nieuwenhuys, R., Am. Zool. 22 (1982) 287

7 Northcutt, R. G, and Butler, A. B., Brain Res. 190 (1980) 333.

8 Luiten, P. G. M., Brain Res. 220 (1981) 343.

9 Senn, D.G., Acta anat. 65, Suppl. 52 (1966) 1.

10 Evan, A.P., Demski, L. S., and Saland, L.C., Cell Tiss. Res. 166 (1976) 521.

11 Demski, L.S., Evan, A.P., and Saland, L.C., J. comp. Neurol. 161 (1975) 483 .

12 Demski, L.S., and Knigge, K.M., J. comp. Neurol. 143 (1971) 1.
13 Crosby, E.C., and Showers, M.J., in: The Hypothalamus, p. 61 Eds W. Haymaker, E. Anderson and W.J.H. Nauta. C.C. Thomas, Springfield 1969.

14 Holmes, R.L., and Ball, J. N., The pituitary gland. Cambridge University Press, 1974

15 Senn, D. G., Zool. J. Linn. Soc. 73 (1981) 343

16 Finck, W., PhD Thesis, in preparation

17 Fryer, J. N., and Maler, L., Cell Tiss. Res. 218 (1981) 93.

18 Gielen, J. Th., and Therlou, M., Cell Tiss. Res. 228 (1983) 43.

19 Robertson. D. R., Science 177 (1972) 1007

20 Fricke, H.W., Z. Tierpsychol. 50 (1979) 313.

21 Fricke, H.W., Naturwissenschaften 61 (1974) 367.

22 Fricke, H.W., Z. Tierpsychol. 61 (1983) 71.

23 Gold, J.B., in: Fish Physiology, vol. 8, p. 353. Eds W.S. Hoar and D.J. Randall. Academic Press, New York 1979.

$0014-4754 / 84 / 070725-03 \$ 1.50+0.20 / 0$

(C) Birkhäuser Verlag Basel, 1984

\title{
Crown ethers which influence cardiac and respiratory muscle contractility ${ }^{1}$
}

\author{
R.C. Kolbeck ${ }^{2}$, L. B. Hendry ${ }^{3}$, E. D. Bransome ${ }^{3}$ and W.A. Speir \\ Department of Medicine, Medical College of Georgia, Augusta (Georgia 30912, USA), 7 July 1983
}

Summary. Guinea-pig tracheal smooth muscle and heart muscle demonstrated a variety of in vitro positive and negative inotropic responses to concentrations of crown ethers in the nmole/l to $\mu$ mole/l range. It is suggested that these ionophoretic compounds have potential as therapeutic agents.

The chemistry of crown ethers has developed rapidly in the years since Pedersen first described their synthesis in $1967^{4}$. These macrocyclic polyethers readily bind a wide range of cations including such physiologically important ions as $\mathrm{Ca}^{+}+$, $\mathrm{Na}^{+}$, and $\mathrm{K}^{+}$. In that cations of appropriate size fit into the heteroatom binding site in the crown ether ring, alterations in either ring size or side chain structure can alter the intensity of ionic binding and result in a diversity of physicochemical properties $^{5-11}$. Frensdorff ${ }^{12}$ described the ionophoretic properties of crown ethers, and demonstrated the ability of these compounds to selectively transport ions from aqueous solutions across hydrophobic membranes by a process of carrier translocations. Behr and his coworkers ${ }^{13}$ recently reported that solidstate models of biological transmembrane channel complexes consist of groups of functionalized macrocyclic polyethers. With the exceptions of the work of Gunther et $\mathrm{al}^{14}$ and Achenbach et al. ${ }^{15}$ who studied cryptands as possible $\mathrm{Na}^{+}$and $\mathrm{K}^{+}$ ionophores in cardiac purkinje fibers, little informations has been published concerning the physiological effects of crown ethers on muscle or upon the ionic transport mechanisms responsible for the development of muscle tension. The present studies examined a selected group of crown ethers in an attempt to discern possible structure function relationship in 2 in vitro muscle systems. The guinea-pig tracheal smooth muscle ${ }^{16}$ and perfused heart muscle demonstrated a wide range of positive and negative contractile responses to crown ethers.

Materials and methods. Male Hartley guinea-pigs weighing $350-450 \mathrm{~g}$ were killed by a sharp blow to the head. Following midsternal thoracotomy, both the trachea and the heart were rapidly excised and immersed in cold oxygenated physiological medium the composition of which was as follows (mmole/ 1 ): $\mathrm{Na}^{+} 126.9 ; \mathrm{K}^{+} 5.8 ; \mathrm{Ca}^{++} 2.5 ; \mathrm{Mg}^{++} 1.2 ; \mathrm{Cl}^{-} 127.7 ; \mathrm{HCO}_{3}^{-}$ $8.9 ; \mathrm{H}_{2} \mathrm{PO}_{4}^{-} 1.1$; and glucose 11.0 .

Tracheal ring segments. Extraneous tissue was removed from 